Tropical Journal of Pharmaceutical Research July 2018; 17 (7): 1415-1422

ISSN: $1596-5996$ (print); 1596-9827 (electronic)

(C) Pharmacotherapy Group, Faculty of Pharmacy, University of Benin, Benin City, 300001 Nigeria.

\title{
Perceived causes of prescribing errors by physicians: A qualitative study
}

\author{
Basmah Al-Fageh ${ }^{1}$, Hisham Aljadhey², Mansour A Mahmoud ${ }^{3 \star}$, Nouf Al-Fadel' \\ Mohamed Azmi Hassali ${ }^{4}$, Bryony Dean Franklin ${ }^{5}$ \\ ${ }^{1}$ King Saud University, Department of Clinical Pharmacy, ${ }^{2}$ Saudi Food and Drug Authority, Riyadh, ${ }^{3}$ Taibah University, Clinical \\ and Hospital Pharmacy Department, College of Pharmacy, Taibah University, Al-Madinah Al-Munawara, Saudi Arabia, \\ ${ }^{4}$ Discipline of Social and Administrative Pharmacy, School of Pharmaceutical Sciences, Universiti Sains Malaysia, Penang, \\ Malaysia, ${ }^{5}$ Centre for Medication Safety and Service Quality, UCL School of Pharmacy/Imperial College Healthcare NHS Trust, \\ London, United Kingdom
}

*For correspondence: Email: Mammm.99@gmail.com; Tel: +966 530187594

Sent for review: 8 March 2018

Revised accepted: 19 June 2018

\begin{abstract}
Purpose: To explore physicians' perceived causes of prescribing errors in Saudi hospitals. Methods: This qualitative study was conducted in three tertiary hospitals in Riyadh, Saudi Arabia: two academic and one government military hospital. A total of 13 physicians from three hospitals participated in two focus groups. Discussions were audiotaped and transcribed verbatim. Transcripts were analysed using thematic content analysis and categorised into themes of error-producing conditions, latent conditions and both successful and unsuccessful defences, based on Reason's Accident Causation Model.

Results: Error-producing conditions included the prescriber, the work environment, the team, the task, the patient and the computer system. The most commonly cited category related to the prescriber's skills and knowledge. The most important latent conditions reported were a shortage of clinical pharmacists followed by lack of computerised physician order entry. The major unsuccessful defences were appropriate references and internet facilities, which were often unavailable.

Conclusion: Several causes of prescribing errors were identified. Lack of clinical pharmacists and lack of computerised prescribing systems are the key issues.
\end{abstract}

Keywords: Prescribing errors, Qualitative study, Computerized prescribing system, Reason's accident causation model

\footnotetext{
This is an Open Access article that uses a funding model which does not charge readers or their institutions for access and distributed under the terms of the Creative Commons Attribution License (http://creativecommons.org/licenses/by/4.0) and the Budapest Open Access Initiative (http://www.budapestopenaccessinitiative.org/read), which permit unrestricted use, distribution, and reproduction in any medium, provided the original work is properly credited.
}

Tropical Journal of Pharmaceutical Research is indexed by Science Citation Index (SciSearch), Scopus, International Pharmaceutical Abstract, Chemical Abstracts, Embase, Index Copernicus, EBSCO, African Index Medicus, JournalSeek, Journal Citation Reports/Science Edition, Directory of Open Access Journals (DOAJ), African Journal Online, Bioline International, Open-J-Gate and Pharmacy Abstracts

\section{INTRODUCTION}

Prescribing errors are common worldwide, and preventable [1]. For example, a study carried out in different US hospitals reported that prescribing errors occur in $0.4-1.9 \%$ of all medication orders, and cause harm in about $1 \%$ of all patients [2]. In the United Kingdom, a recent study identified prescribing errors in $8.8 \%$ of medication orders [3]. In Saudi Arabia, to date few studies have been conducted to determine the incidence of prescribing errors [4]. One study identified $113(7.1 \%)$ prescribing errors in 1,580 
medication orders in a teaching hospital [5], and another reviewed medical charts of 977 patients and found that $72.7 \%$ of medication errors occurred in the ordering stage of medication use [6]. A study in a paediatric tertiary care hospital found an error rate of 56 per 100 medication orders with most prevalent error $(22.1 \%$ of errors) involving the dose [7]. In 2006 a two year retrospective review of 10,000 patients' files was conducted in a general hospital and prescribing errors identified in $26.3 \%$ of patients' files [8].

To prevent prescribing errors; the underlying causes need to be evaluated. The majority of studies investigating the causes of prescribing errors have been conducted in the US and UK [9], with the causes including illegible handwriting, ambiguous orders, inadequate dosage calculation, improper transcription, inadequate training, and inappropriate abbreviations [9]. There have been few studies of the causes of prescribing errors in the developing countries and it is not known whether the causes are similar, or different, to those elsewhere. Reasons for possible differences include differences in the healthcare system, culture, and working environment.

\section{METHODS}

\section{Study design}

Focus group discussion with physicians from different clinical areas were conducted; discussions were analysed using a qualitative approach.

\section{Setting}

Participants were recruited from three tertiary hospitals in Riyadh, Saudi Arabia: two academic and one government military hospital. At the time of the study the hospitals did not have computerized physician order entry (CPOE) systems in routine use. All hospitals had clinical pharmacy services, but these were based mostly in critical care areas.

\section{Participant recruitment}

Physicians with experience in writing prescriptions were recruited from different specialties and with different levels of clinical experience, via personal e-mails and phone calls. A reminder of the invitation was sent after two weeks to all participants and those who did not respond within another week were considered non-respondents. Participants who agreed to participate were contacted to set an appropriate time and place for the focus group discussions.

\section{Theoretical framework}

Human error theories have been used to analyse errors in the nuclear power and aviation environments. For a few decades, they have increasingly been applied to clinical practice settings [10]. One of the most commonly used to investigate the cause of prescribing errors is Reason's accident causation model [11]. This model includes four stages: latent conditions, error and violation producing conditions, active failures and defences. Latent failures describe the organizational process and management decisions that generate an environment where error and violation producing conditions and active failures occur. Active failures are the slips, lapses, mistakes and violations made by those at the frontline of the system. Defenses involve protection against hazards and reduce the consequences of failure and may be successful or unsuccessful.

\section{Focus groups}

A focus group guide (Appendix 1) was developed by the authors after conducting a literature review of studies with similar objectives $[12,13]$. The guide explored participants' personal experiences with prescribing errors and their perceptions around what might have caused them, as well as preventive measures that can be taken to avoid those errors in the future. Two focus group discussions were held. The first lasted for one hour and forty minutes, and the second for one hour and twenty minutes. Both were managed by a moderator and audio taped. The discussion was held in English as the official language used among healthcare staff in Saudi Arabia.

\section{Ethical approval}

Ethical approval was obtained from the Institutional Review Board Committee at King Saud University (project no. 13-1022). In addition, a consent form was signed by every participant before the interviews. The study followed the International Ethical Guidelines for Health-Related Research involving humans [14].

\section{Data analysis}

The discussions were transcribed verbatim by the researcher, and then subject to thematic content analysis by two independent researchers, with a deductive approach $[15,16]$. Data were categorised into themes based on the accident causation model [11], focusing on the 
latent failures, error producing conditions, and defences. The resulting themes were then discussed among the two researchers to agree on the final analysis.

\section{RESULTS}

A total of 44 physicians were invited through emails or phone calls, of whom 24 responded. After fixing dates of the focus group discussions, 11 of the 24 could not attend the discussion. Ultimately, 13 physicians attended the focus groups (seven in the first group and six in the second group). The majority of the participants were male, predominantly working in teaching hospitals (Table 1 ).

\section{Error-producing conditions:}

We identified examples of six major groups of error producing conditions (the individual prescriber, the work environment, the team, the task, the patient, and the technology).

\section{Individual prescriber}

The individual prescriber was the major error producing condition recognised by participants. The most important factor was perceived to be the prescriber's skills and knowledge, including physician handwriting, dose calculation skills, physician knowledge, and experience. Perception of risk was another factor believed to affect the prescriber, some prescribers reported over-confidence in prescribing certain medications; this may also include prescribing the same medication repeatedly, which can lead to prescribing error. Furthermore, the physical health of a prescriber, including tiredness, stress and lack of recovery time, was perceived to affect the physician's performance:

"During calls and heavy duty sometimes you have mental block so, you think about something and you write something else and you may even pronounce it or say it in a way that can cause death e.g. One of my colleagues asked one of the technicians to prepare potassium chloride $(\mathrm{KCl})$ and he meant calcium chloride $\left(\mathrm{CaCl}_{2}\right)$. He should not have pronounced it as an abbreviation rather he should have said calcium chloride in full. The use of abbreviation in a prescription especially verbal orders can result in a disaster." (FG1.P2)

\section{Work environment}

Physicians reported that high workload and time pressure can affect their concentration and subsequently lead to prescribing errors. Furthermore, they raised the situation in which the physician examines more than one patient at the same time, usually including one or more family members, and consequently they might mix the prescriptions, for example:

Table 1: Participant demographic characteristics

\begin{tabular}{|c|c|c|c|c|c|c|}
\hline Participant & Gender & Profession & Speciality & Unit & Experience & Hospital type $^{\star}$ \\
\hline FG1P1 & Male & Consultant & Ophthalmology & $\begin{array}{l}\text { Medicine \& } \\
\text { surgical }\end{array}$ & 13 years & $\begin{array}{c}\text { Governmental } \\
\text { (1) }\end{array}$ \\
\hline FG1P2 & Male & Resident & Anaesthesiology & $\begin{array}{c}\text { Not } \\
\text { specified }\end{array}$ & 5 years & Academic \\
\hline FG1P3 & Male & Consultant & Ophthalmology & Surgical & 15 years & $\begin{array}{c}\text { Governmental } \\
\text { (1) }\end{array}$ \\
\hline FG1P4 & Male & Senior registrar & Family medicine & $\begin{array}{c}\text { Not } \\
\text { specified }\end{array}$ & 7 years & $\begin{array}{c}\text { Governmental } \\
\text { (2) }\end{array}$ \\
\hline FG1P5 & Male & Senior registrar & Family medicine & Medicine & 40 years & $\begin{array}{c}\text { Governmental } \\
\text { (2) }\end{array}$ \\
\hline FG1P6 & Male & Demonstrator & Public health policy & Medicine & 3 years & Academic \\
\hline FG1P7 & Male & Senior registrar & Family medicine & Medicine & 10 years & $\begin{array}{c}\text { Governmental } \\
\text { (2) }\end{array}$ \\
\hline FG2P1 & Female & Consultant & Family medicine & $\begin{array}{c}\text { Not } \\
\text { specified }\end{array}$ & 20 years & $\begin{array}{c}\text { Governmental } \\
\text { (2) }\end{array}$ \\
\hline FG2P2 & Female & Senior registrar & General surgery & Surgical & 6 years & Academic \\
\hline FG2P3 & Female & Resident & General surgery & Surgical & 5 years & Academic \\
\hline FG2P4 & Male & Consultant & Anaesthesiology & Surgical & 15 years & Academic \\
\hline FG2P5 & Male & Resident & Paediatrics & Medicine & 4 years & Academic \\
\hline FG2P6 & Male & Consultant & $\begin{array}{l}\text { Paediatrics } \\
\text { gastroenterology }\end{array}$ & Medicine & 35 years & Academic \\
\hline
\end{tabular}


"I examined three paediatric patients for one mother then under time pressure I wrote medication for patient $A$ in the sheet of patient $B$ but fortunately I realized the mistake and called them before dispensing." (FG1.P7)

\section{The team}

The participants felt that the relationship between the pharmacist and physician is not wellestablished:

\begin{abstract}
"Pharmacists have their own complexes concerning the physician they always want to prove that they are right and they search for our mistakes to prove that they know more. This attitude make them our enemies that's why we don't like to deal with them. I believe that this is one of the risk of medication errors." (FG1.P7)
\end{abstract}

Inappropriate communication between pharmacists and physicians, especially when prescribing rarely used medications or alternative medications, were reported to negatively affect teamwork. In addition, language barriers that result due to the multinational composition of health care providers were another factor. For example, participants reported that sometimes nurses misinterpreted physicians' verbal medication orders due to language barriers due to different English accents that could be misleading. Lack of supervision of junior physicians by more doctors was also mentioned. It was reported that in many cases the seniors depend on juniors for writing prescriptions and let them do the dose calculation without supervision; they then sign the prescription without checking if the correct medication regimen has been prescribed.

\section{The task}

Repeat prescriptions were reported to be one of the situations in which prescribing errors occur. It was felt that some junior doctors do not know how to follow the repeat prescription guidelines (e.g. no repeats for short-term antibiotics) and instead, they copy what is written in the pharmacy computer system, so the patient continues taking medication without a clinical indication.

"An example of certain guidelines that the physicians follow is: no repeat for temporary medication like antibiotics or flu medication but some juniors don't follow the guidelines. They just copy what is written in the computer, patient may see another medical doctor and keep refilling for years without changing the dose or drug." (FG2.P1)
Another high-risk task was prescribing medication that needs therapeutic drug monitoring, such as anticonvulsants being prescribed on a repeat prescription without checking that a drug level had been measured.

\section{The patient}

Patients themselves were considered to be one of the error producing conditions. The participants identified many factors that affect the patients and contribute to prescribing errors such as the patient's education, complexity of the patient's case and the patient's habits regarding medication use which can make it challenging to ascertain a drug history:

"Patients like to shop for medication from private and public governmental hospitals, sometimes they collect a lot of medicines, including different brands of the same medication." (FG2.P1)

Furthermore, the issue of patients' honesty regarding their medications or medical history was raised by the participants.

"Patients sometimes do not tell the true history, sometimes a specific information related to medicines is important to help in prescribing decision. If this information is missing, the error will happen." (FG2.P4)

\section{Technology}

Although not part of Reason's original accident causation model, technology was a common theme raised in the focus groups and we therefore report this as a separate theme. Most of the participants reported that they still rely on hand-written prescriptions because in their institutions they do not have CPOE. On the other hand, respondents who had worked in organisations that have CPOE also reported problems with inappropriately overriding computer alerts. This may lead to medication errors, especially if the pharmacist did not communicate with the physician if he or she suspected something was wrong. Another reported error producing condition was expecting too much from the computer system, such as expecting alerts for dose adjustments based on creatinine clearance.

"We don't have computerized system that alerts the physician in case if the patient has a problem that you need to check before prescribing certain medications, for example high urea creatinine which require dose reduction." (FG2.P2) 


\section{Latent conditions}

The major latent conditions reported were related to the clinical pharmacist, followed by training and the management as described below.

\section{Clinical pharmacists}

All participants agreed on the important role of the clinical pharmacist in reducing the risk of prescribing errors. However, they also complained about the lack of clinical pharmacists. They mentioned that in most hospitals there are not enough clinical pharmacists to have one assigned for each department, for example there is no nephrology clinical pharmacist, cardiology clinical pharmacist and so on.

\section{Training}

An important issue was the lack of training in writing an ideal prescription:

"When I was an intern nobody instructed me or gave me a lecture about what drugs I can prescribe as an intern. The instructions came mainly from the nurses they ask me to give this medication in that dose, not from my senior, resident or consultant." (FG1.P2)

\section{Management}

The authority of prescribing is another issue when recently qualified health care providers are allowed to write prescriptions, such as new graduates with no experience of prescribing, interns and even sometimes nurses. Some of the participants blamed the policy and procedures of prescribing and suggested more restrictive regulations on how to write prescriptions and which abbreviations they must avoid. They highlighted the importance of having a physician's registration number which describes health care provider type, classification and specialization on the prescription then the pharmacist can check whether or not a physician is allowed to prescribe a specific medication.

\section{Defences}

Our findings identified both successful defences and those that were inadequate or unsuccessful because of latent conditions.

\section{Successful defences}

Four measures were reported as potentially successful defences. The first was CPOE. One of the participants who had a role in the quality department shared his experience when they compared the prescribing errors before and after using CPOE in a discrete project, and they found a reduction in some types of medication errors, such as miss-spelling of hand written medication name or dose.

"We have experience with electronic prescription which was a subject of a quality assessment project in our hospital which only applied to paediatric inpatients department. They compared the medication error before and after implementation of electronic prescription. They found a reduction in medication errors such as miss spelling of hand written medication name or dose, but there were no reduction in other medication errors." (FG2.P5)

Another successful defence cited was the clinical pharmacist, where available, as they have an important role in deciding the medication regimen to be prescribed.

"Clinical pharmacist is important in helping us in our practice. I am not aware about the small details of the medication, he is helping to prevent mistakes." (FG1.P1)

"Role of clinical pharmacist is very important, I feel relaxed when I write a prescription knowing that he will look at it after me then he might modify it or ask me to do some changes." (FG1.P3)

Drug information centres and quality departments were also reported to play a successful role in reducing prescribing errors by providing accurate information regarding medication.

\section{Unsuccessful defences}

One of the most important defences to prevent prescribing errors was felt to be the pharmacist but this is also an imperfect defence, due to similar reasons mentioned by the participants: high workload and lack of knowledge. In some instances, it was reported that pharmacists could not read the physician's illegible handwriting and found it difficult to communicate with the physician to clarify what is written:

"Pharmacists sometimes miss read the prescriptions, one time I wrote Xatral $\AA$ for benign prostatic hyperplasia (BPH) and they gave Xyzal ${ }^{\circledR}$ which is antihistamine and they didn't call to make sure of the medication." (FG1.P7) 
Human error is one of the main causes of prescribing errors, which can be overcomed by double checking the prescriptions, especially for high alert medications; however if this was not done, the defence was unsuccessful:

"Sometimes the consultants ask the junior residents and intern to prescribe the medicine verbally, However; they may write wrong dose, duration or frequency, therefore we need to double check junior doctors prescriptions (FG2.P2)

Many other unsuccessful defences were raised by the participants, including proper resources and internet facilities which were sometimes unavailable on the ward, ineffective error reporting systems and lack of accountability, and finally no national filing system for medical records. In this latter case the patient may followup with different institutions for the same disease and be prescribed the same medication with different brand names resulting in duplication of therapy.

\section{DISCUSSION}

In this study, six groups of error producing conditions have been explored. The main latent conditions leading to prescribing errors were the lack of clinical pharmacists, insufficient training on how to write appropriate prescriptions and the lack of a CPOE system in most hospitals. The clinical pharmacist's role and the presence of a CPOE system in addition to the role of drug information centres and quality departments are considered as potentially successful defences against prescribing errors. On the other hand, many unsuccessful defences were also identified, e.g. deficiency of proper resources, absence of effective error reporting systems, and finally poor double-checking systems.

The results of several previous studies aiming to explore the causes of prescribing errors were based on Reason's model of accident causation and generally had similar results [12,17-23]. The PROTECT study, which focused on prescribing outcomes for trainee doctors in England, stated that "None of the doctors interviewed had reported their errors through the hospital reporting system" which corresponded with what we found regarding ineffective error reporting programs as an unsuccessful defence against prescribing errors [22]. Nigerian junior doctors also complained of lack of training in prescribing skills and the absence of reference books and guidelines to avoid prescribing errors [17].
A focus group design was used, which allowed the researchers to generate new thinking through group dynamics and result in much more indepth discussion. It also allowed each expression and attitude of the participants to be perceived and observed. The participants were from different specialities and included a mixture of junior and senior doctors, to obtain different opinions and stimulate the discussion. During the analysis we followed Reason's accident causation model.

Recommendations to reduce errors include activating the role of continuous medical education for both prescribers and pharmacists, which could decrease errors resulting from lack of knowledge. Addressing the need for qualified clinical pharmacists could also contribute to overcoming prescribing errors. Counter-signing by another physician and double-checking by a pharmacist, especially for high alert medication, might decrease the chance of human errors. The problem with a physician's hand-writing may be overcome by having an efficient CPOE system, which at the same time facilitates the prescribing process although it may also give rise to new types of error [24].

Having a national electronic medical record system may limit the medication duplication problem and play a part in establishing a clear picture of a patient's medical and medication history, in order to prevent any error or duplication in the therapeutic plan. Furthermore, it is important to reconsider the repeat prescription policy and procedure or at least make sure that it is applied properly. Finally, in order to prevent medication errors due to verbal orders, policies that insure confirmation of verbal orders should be implemented.

\section{Limitations of the study:}

Possible limitations are that one cannot rule out the chance of a participant's opinion being influenced by others during the discussion. We could not identify active failures because data were based on the physicians' experiences and not on specific errors that they had made. We identified the perceived causes of prescribing errors in Saudi Arabian hospitals and certain measures can be taken to prevent these errors in order to establish safer prescribing practices. However, there are challenges in making significant changes with regard to some issues, such as the nature of society and the complexity of patient cases, work load and the language barrier that result from a multinational health care team. 


\section{CONCLUSION}

Prescribing errors are serious problems that threaten patient safety. The causes of these errors in Saudi Arabia are multifactorial including both health care provider and patient behaviours. Research is now needed to develop and evaluate interventions to reduce these errors in the Saudi Arabian context.

\section{DECLARATIONS}

\section{Acknowledgement}

This research project was supported by a grant from the "Research Centre of the Female Scientific and Medical Colleges", Deanship of Scientific Research, King Saud University.

The Centre for Medication Safety and Service Quality is partly funded by the UK National Institute for Health Research (NIHR) Imperial Patient Safety Translational Research Centre. The views expressed are those of the author(s) and not necessarily those of the NHS, the NIHR or the Department of Health.'

The research team thanks all prescribers who kindly took part in this study by giving their time to participate in the focus group. Furthermore, we thank all who assisted in contacting and recruiting the participants.

\section{Conflict of interest}

No conflict of interest is associated with this work.

\section{Contribution of authors}

We declare that this work was done by the authors named in this article and all liabilities pertaining to claims relating to the content of this article will be borne by the authors. BA, HA, MAM, MAH and BDF designed the study. BA had full access to all of the raw data in the study and takes responsibility for the integrity of the data and the accuracy of the data analysis. BA and MAM analysed the study data. BA wrote the first draft of the manuscript. BDF critically reviewed the manuscript. The final draft of the manuscript was reviewed and approved by all authors.

\section{REFERENCES}

1. Lewis PJ, Dornan T, Taylor D, Tully MP, Wass V, Ashcroft DM. Prevalence, incidence and nature of prescribing errors in hospital inpatients: a systematic review. Drug Saf. 2009; 32(5): 379-389.

2. Lesar TS, Briceland L, Stein DS. Factors related to errors in medication prescribing. J AMA 1997; 277(4): 312-317.

3. Ashcroft DM, Lewis PJ, Tully MP, Farragher TM, Taylor $D$, Wass V, Williams SD, Dornan T.. Prevalence, Nature, Severity and Risk Factors for Prescribing Errors in Hospital Inpatients: Prospective Study in 20 UK Hospitals. Drug Saf 2015; 38 (9): 833-843.

4. Mahmoud MA, Aljadhey $\mathrm{H}$, Hassali MA. Prescribing errors incidence in hospitalized Saudi patients: Methodology considerations. Saudi Pharm J. 2014; 22 (4): 388-389.

5. Al-Dhawailie AA. Inpatient prescribing errors and pharmacist intervention at a teaching hospital in Saudi Arabia. Saudi Pharm J 201; 19(3): 193-196.

6. Aljadhey H, Mahmoud MA, Mayet A, Alshaikh M, Ahmed $Y$, Murray MD, Bates $D$. Incidence of adverse drug events in an academic hospital: a prospective cohort study. Int J Qual Health Care 2013; 25(6): 648-655.

7. Al-Jeraisy MI, Alanazi MQ, Abolfotouh MA. Medication prescribing errors in a pediatric inpatient tertiary care setting in Saudi Arabia. BMC Res Notes 2011; 4: 294.

8. Dibbi HM, Al-Abr ashy HF, Hussain WA, Fatani MI, Karima TM. Causes and outcome of medication errors in hospitalized patients. Saudi Med J 2006; 27(10): 1489-1492.

9. Tully MP, Ashcroft DM, Dornan T, Lewis PJ, Taylor D, Wass $V$. The causes of and factors associated with prescribing errors in hospital inpatients: a systematic review. Drug Saf. 2009; 32(10): 819-836.

10. Vincent C, Taylor-Adams S, Chapman EJ, Hewett D, Prior S, Strange $P$, Ann T. How to investigate and analyse clinical incidents: clinical risk unit and association of litigation and risk management protocol. BMJ. 2000; 320 (7237): 777-781.

11. Reason J. Human error. Cambridge: University of Cambridge; 1990.

12. Dean B, Schachter M, Vincent $C$, Barber N. Causes of prescribing errors in hospital inpatients: a prospective study. Lancet. 2002; 359(9315): 1373-1378.

13. Franklin BD, Reynolds M, Shebl NA, Burnett S, Jacklin A. Prescribing errors in hospital inpatients: a three-centre study of their prevalence, types and causes. Postgrad Med J. 2011; 87(1033): 739-745.

14. World Health Organization, and Council for International Organizations of Medical Sciences. International ethical guidelines for health-related research involving humans, 2016.

15. Clarke VBV. Using thematic analysis in psychology. Qualit Res Psychol 2006; 3(2): 77-101.

16. Harding J. Qualitative data analysi s from start to finish. London: SAGE; 2013.

17. Ajemigbitse $A A$, Omole MK, Osi-Ogbu OF, Erhun WO. A qualitative study of causes of prescribing errors among junior medical doctors in a Nigeria in-patient setting. Ann Afr Med. 2013; 12(4): 223-231. 
18. Buckley MS, Erstad BL, Kopp BJ, Theodorou AA, Priestley $G$. Direct observation approach for detecting medication errors and adverse drug events in a pediatric intensive care unit. Pediatr Crit Care Med 2007; 8(2): 145-152.

19. Coombes ID, Stowasser DA, Coombes JA, Mitchell C. Why do interns make prescribing errors? A qualitative study. Medical J Aust. 2008; 188(2): 89-94.

20. Kopp BJ, Erstad BL, Allen ME, Theodorou AA, Priestley $G$. Medication errors and adverse drug events in an intensive care unit: direct observation approach for detection. Crit Care Med 2006; 34(2): 415-425.

21. Ross S, Ryan C, Duncan E, Francis J, Johnston M, Ker S, Lee J, MacLeod J, Maxwell S, McKay G, McKay J, Webb $D$, Bond C. Perceived causes of prescribing errors by junior doctors in hospital inpatients: a study from the PROTECT programme. BMJ Qual Saf 2013; 22(2): 97-102.

22. Ryan C, Ross S, Davey $P$, Duncan E, Francis J, Fielding S, Johnston M, Ker J, Lee AJ, MacLeod MJ, Maxwell S, McKay G, McKay J, Webb D, Bond C. Prevalence and causes of prescribing errors: the Prescribing Outcomes for Trainee Doctors Engaged in Clinical Training (PROTECT) study. PloS One 2014; 9(1): e79802.

23. Slight SP, Howard R, Ghaleb M, Barber N, Franklin BD, Avery AJ. The causes of prescribing errors in English general practices: a qualitative study. $\mathrm{Br} J$ Gen Pract. 2013; 63(615): e713-e20.

24. Charles K, Cannon M, Hall R, Coustasse A. Can utilizing a computerized provider order entry (CPOE) system prevent hospital medical errors and adverse drug events? Perspect Health Inf Manag 2013; 615: e713e720. 